\title{
The French Emergency Department OSCOUR Network: Evaluation After a 10-year Existence
}

\author{
Anne Fouillet*, Vanina Bousquet, Isabelle Pontais, Anne Gallay and Céline Caserio- \\ Schönemann
}

French Institute for Public Health Surveillance (InVS), Saint Maurice, France

\section{Objective}

Implemented 10 years ago, the French emergency department surveillance system (Oscour Network) has been assessed using four major evaluation criteria in syndromic surveillance: stability, coverage, data quality and utility.

\section{Introduction}

After the major impact of the 2003 heat wave, France needed a reactive, permanent and national surveillance system enabling to detect and to follow-up various public health events all over the territory including overseas [1-2]. In June 2004, the French syndromic surveillance system based on the emergency department (ED) has been implemented by the national institute for public health surveillance (InVS). Beginning with 23 ED in 2004, the network has progressively included new ED and several steps have contributed to accelerate this permanent increase. A first evaluation of this data source was conducted for the specific surveillance of heat wave [3].

\section{Methods}

After 10 years of experience, four evaluation criteria on essential characteristics for a syndromic system are explored:

1/ stability and regularity of data transmission, evaluated by a prospective calculation of the proportion of ED having transmitted their data on time (daily transmission is expected),

$2 /$ the national coverage, calculated by the proportion of ED included in the network and the proportion of the daily ED attendances in the total number of attendances in France,

3/ the data quality, particularly for the demographic and medical information (ICD10 codes),

and $4 /$ the utility of the system, evaluated by describing the publichealth situations for which the system has been used, regarding the objectives of the system (detection and situational awareness).

\section{Results}

In August 2014, about 600 ED are included in the Oscour network for the syndromic surveillance, recording $80 \%$ of the national total attendances. The 26 French regions are covered by the system, with a coverage rate ranging from $21 \%$ to $100 \%$ in 5 regions.

The transmission from data providers to InVS is very stable and regular: every day, the institute receives about 40,000 attendances recorded the previous day (d-1) by about $85 \%$ of the 600 ED participating to the network. The $15 \%$ of missing ED generally send their data in the two following days.

More than $98 \%$ of the demographic information (date of birth and gender) are correctly recorded. $75 \%$ of the medical diagnoses coded in ICD10 are recorded. In 2013, about 12,800 different ICD10 codes have been used by the physicians. This major variety of codes ensures a large surveillance based on various syndromic indicators. Surveillance is performed routinely both at regional and national level, based on daily and weekly dashboards monitoring about 60 indicators.

During the last decade, few events have been detected by the system, even if that was the initial objective of the system. However, the system has often allowed for situational awareness of both unexpected events (air pollution episodes, floods, cyclone, measles, chikungunya emergence) and usual events (heat/cold waves, flu and winter usual epidemics, dengue outbreak,...). The system has also contributed to the surveillance of the population health during mass gatherings (2012 Olympic Games, 2014 World Equestrian Games, G8/G20 summit).

\section{Conclusions}

Since the beginning of the system, the coverage and data quality have permanently been increasing. The mandatory transmission of ED data set up in july 2013 helped recently to improve the national coverage but with some adverse effects on coding practices which have to be carefully monitored. With a 10-year historical database, robust statistical methods can be implemented for detection. Reflexions are ongoing to complete the system with early medical management data from the pre-hospital period and include the French medical rescue units into the syndromic surveillance system.

\section{Keywords}

Emergency Department; Evaluation; France

\section{Acknowledgments}

To emergency department data providers and InVS regional units for their substantial contribution to the system.

\section{References}

[1] Josseran L, Nicolau J, Caillère N, Astagneau P, Brücker G. Syndromic surveillance based on emergency department activity and crude mortality: two examples. Euro Surveill 2006;11:225-9.

[2] Caserio-Schönemann C, Bousquet V, Fouillet A, Henry V. Le système de surveillance syndromique SurSaUD (R). Bull Epidémiol Hebd 2014;3-4:38-44.

[3] Josseran L, Fouillet A, Caillère N, Brun-Ney D, Ilef D, et al. (2010) Assessment of a Syndromic Surveillance System Based on Morbidity Data: Results from the Oscour® Network during a Heat Wave. PLoS ONE 5(8): e11984. doi:10.1371/journal.pone.0011984

\section{*Anne Fouillet}

E-mail: a.fouillet@invs.sante.fr 